\title{
Gene expression profile and genomic alterations in colonic tumours induced by 1,2-dimethylhydrazine $(\mathrm{DMH})$ in rats
}

\author{
Angelo Pietro Femia ${ }^{1}$, Cristina Luceri ${ }^{1}$, Simona Toti ${ }^{1}$, Augusto Giannini ${ }^{2}$, Piero Dolara ${ }^{1}$, Giovanna Caderni ${ }^{{ }^{*}}$
}

\begin{abstract}
Background: Azoxymethane (AOM) or 1,2-dimethylhydrazine (DMH)-induced colon carcinogenesis in rats shares many phenotypical similarities with human sporadic colon cancer and is a reliable model for identifying chemopreventive agents. Genetic mutations relevant to human colon cancer have been described in this model, but comprehensive gene expression and genomic analysis have not been reported so far. Therefore, we applied genome-wide technologies to study variations in gene expression and genomic alterations in $\mathrm{DMH}$-induced colon cancer in F344 rats.
\end{abstract}

Methods: For gene expression analysis, 9 tumours (TUM) and their paired normal mucosa (NM) were hybridized on $4 \times 44 \mathrm{~K}$ Whole rat arrays (Agilent) and selected genes were validated by semi-quantitative RT-PCR. Functional analysis on microarray data was performed by GenMAPP/MappFinder analysis. Array-comparative genomic hybridization (a-CGH) was performed on 10 paired TUM-NM samples hybridized on Rat genome arrays $2 \times 105 \mathrm{~K}$ (Agilent) and the results were analyzed by CGH Analytics (Agilent).

Results: Microarray gene expression analysis showed that Defcr4, Igfbp5, Mmp7, Nos2, S100A8 and S100A9 were among the most up-regulated genes in tumours (Fold Change (FC) compared with NM: 183, 48, 39, 38,36 and 32, respectively), while Slc26a3, Mptx, RetIna and Muc2 were strongly down-regulated (FC: -500; -376, -167, -79, respectively). Functional analysis showed that pathways controlling cell cycle, protein synthesis, matrix metalloproteinases, TNF $\alpha / N F k B$, and inflammatory responses were up-regulated in tumours, while Krebs cycle, the electron transport chain, and fatty acid beta oxidation were down-regulated. a-CGH analysis showed that four TUM out of ten had one or two chromosomal aberrations. Importantly, one sample showed a deletion on chromosome 18 including Apc.

Conclusion: The results showed complex gene expression alterations in adenocarcinomas encompassing many altered pathways. While a-CGH analysis showed a low degree of genomic imbalance, it is interesting to note that one of the alterations concerned Apc, a key gene in colorectal carcinogenesis. The fact that many of the molecular alterations described in this study are documented in human colon tumours confirms the relevance of DMHinduced cancers as a powerful tool for the study of colon carcinogenesis and chemoprevention.

\section{Background}

Colorectal cancer is one of the most common neoplastic diseases in the Western World [1], developing through a multistage process which involves the accumulation of genetic and epigenetic alterations. Experimental models mimicking this disease in rodents, such

\footnotetext{
* Correspondence: giovanna.caderni@unifi.it
'Department of Pharmacology, University of Florence, 6 Viale Pieraccini,

* Correspondence: giovanna.caderni@unifi.it
1Department of Pharmacology, University of Florence, 6 Viale Pieraccini, 50139 Florence, Italy
}

(c) 2010 Femia et al; licensee BioMed Central Ltd. This is an Open Access article distributed under the terms of the Creative Commons Attribution License (http://creativecommons.org/licenses/by/2.0), which permits unrestricted use, distribution, and reproduction in any medium, provided the original work is properly cited. (AOM)-induced carcinogenesis, provide a tool for the understanding of the molecular alterations arising in human colon cancer. Inbred strains such as F344 rats, which are frequently used in these experiments, are relatively uniform and the tumors developing after induction show phenotypic and genotypic features similar to those observed in human sporadic colon cancers, notably activation of Wnt signaling pathway and mutations in Kras and Apc genes [2]. Importantly, as 1,2-dimethylhydrazine (DMH) or azoxymethane 
AOM/DMH-induced tumours develop almost exclusively in the colon, at variance with other experimental models in which carcinogenesis develops mainly in the small intestine, a site rarely involved in human cancer. Since AOM/DMH tumours are affected by the same dietary variations known to affect human colon carcinogenesis, this model is among the most used and reliable for identification of potentially chemopreventive agents [3].

The advent of genome-wide technologies, such as gene expression microarray and array-based comparative genomic hybridization (a-CGH), has provided the possibility to achieve a comprehensive view of the alterations involved in cancer. Although several papers have been published on human colon tumours [4] and some also in AOM-treated mice [5,6], no studies applying genomewide technology to $\mathrm{DMH}$-induced cancers in rats have been reported. Given these considerations, we thought it of interest to study the gene expression profile of DMHinduced colon tumours in rats with the $44 \mathrm{~K}$ Agilent rat arrays, representing the whole rat genome. Moreover, we were also interested in studying genomic alterations in this experimental model. In fact, although genomic instability in AOM-induced colon cancer in rats was previously reported [7], the technique in that study (Random Amplified Polymorphic DNA (RAPD analysis)) did not give information on the affected loci. On the other hand, using low resolution comparative genomic hybridization $(\mathrm{CGH})$ [8], it has also been reported that AOM-induced tumours in mice have a low level of genomic alterations, making it difficult to draw any conclusions. Given these considerations and the possibility of achieving a comprehensive view of genomic alterations involved in tumors with high-resolution genome-wide technologies, we analyzed DMH-tumours with a-CGH using high resolution arrays $(2 \times 105 \mathrm{~K}$ Agilent rat genome array).

\section{Methods}

\section{Tumour induction and harvesting}

Briefly, 4- to 5-week old male F344 rats (Nossan, Correzzana, Milan, Italy) were fed a high-fat diet based on the AIN-76 diet as previously described [9]. Rats were housed according to the European Union Regulations on the Care and Use of Laboratory Animals [10]; the experimental protocol was approved by the Commission for Animal Experimentation of the Italian Ministry of Health. At 6-7 weeks of age rats $(n=14)$ were treated twice, one week apart, with subcutaneous injections of 1,2-dimethylhydrazine $(150 \mathrm{mg} / \mathrm{kg} \times 2)$. Thirty-two weeks after the first DMH injection, rats were sacrificed by $\mathrm{CO}_{2}$ asphyxiation and colonic tumors harvested as described [11]. At sacrifice, all the rats had colon tumours. One-half of each tumour was cut and stored in RNAlater (Qiagen) while the second half was fixed in buffered formalin for histopathological and immunohistochemical analysis as described [11]. Apparent normal mucosa from each rat was also scraped from the colon and stored in RNAlater (Qiagen) before DNA or RNA extraction.

\section{Histological analysis}

Histological sections of each tumour were stained with hematoxylin and eosin to confirm the presence and type of tumours by histopathological examination, on the basis of the histotype, grading and pattern of growth as described [11].

\section{Microarray hybridization}

\section{RNA isolation, labeling, hybridization and image analysis}

Total RNA was extracted from 9 paired samples of normal mucosa (NM) and adenocarcinomas (TUM) using the RNeasy Midi kit (Qiagen, Milan, Italy). For each hybridization, $18 \mu \mathrm{g}$ of total RNA from each sample (NM or TUM) was used. Each TUM (labeled with Cy5) (CyDye Mono-Reactive Dye Pack, Amersham, Cologno Monzese, Milan, Italy) was individually hybridized on Agilent Whole Rat Genome $4 \times 44 \mathrm{~K}$ microarrays (Agilent Technologies, Palo Alto, CA, USA) using the RNA (labeled with Cy3) from the corresponding NM as reference. As for labeling, we used the indirect labeling method described previously [12]. The hybridization steps were carried out according to the Agilent protocol and images were scanned using a Genepix 4000B microarray scanner (Axon Instruments, Foster City, CA, USA). Image analysis and initial quality control were performed using Agilent Feature Extraction Software v9.5.

\section{Microarray data analysis}

The text files were imported into $\mathrm{R} 2.5 .1$ using the Bioconductor "limma" package 2.8.1 for statistical analysis as reported [13]. Values for control spots and spots that did not meet the quality criteria were flagged. Quality criteria included a minimal spot size, a median/mean ratio of at least 0.9 for each spot, non-saturated intensity for both channels, a signal well above background and a minimal signal intensity for at least one channel. Due to the high number of features that did not meet the quality control criteria, one out of the nine hybridizations was excluded from subsequent analysis. The background-corrected intensities of all microarrays were normalized using the LOESS algorithm as reported [13]. The tumour samples were compared to the corresponding normal mucosa using a paired moderated t-test with the Benjamini-Hochberg correction of the FDR (false discovery rate) for the multiple tests [14].

\section{Functional analysis}

Biological pathway analysis was performed using the GenMAPP/MAPPFinder software tandem [15]. For 
GenMAPP, the "Rn_Std_20070817" gene database and the "Rn_20080619" pathway set were used. MAPPFinder analyses for pathway enrichment were performed for up- and down-regulated genes, separately. MAPPFinder selection criteria were set at Benjamin-Hochberg $p<$ 0.05 . Only statistically significant pathways showing a permuted $p$-value $<0.05$ and a positive (enrichment) $\mathrm{z}$-score $>2$ were selected.

\section{Semi-quantitative RT-PCR}

One microgram of total RNA for each sample (tumour and normal mucosa) was reverse transcribed using 100 units of SuperScript ${ }^{\mathrm{TM}}$ II Reverse Transcriptase (Life Technologies, Milan, Italy) and $1 \times$ random hexamers (Roche Diagnostics, Monza, Italy). Seven out of the 9 paired TUM-NM samples were processed for RT-PCR analysis. The following genes were tested: Defcr4, S100A9, Igfbp5, Slc30a2 and Lrg5 (up-regulated genes); Mptx, Slc26a3, Retnla, Hpgd and Muc2 (down-regulated genes). The list of the primers used is provided in the Additional file 1: List of the primers used for semiquantitative RT-PCR. Each gene was co-amplified with $\beta$-actin gene $(A c t b)$ as internal control as described [16]. PCRs were carried out using cDNA aliquots in a $25 \mu \mathrm{l}$ total volume containing $1 \times \mathrm{PCR}$ buffer, $2 \mathrm{mM} \mathrm{MgCl}_{2}$, $0.5 \mathrm{mM}$ dNTPs, and 1.25 units of Taq polymerase (Sigma-Aldrich, Italy). Primers for each gene were also added (concentration range: $0.16-0.4 \mu \mathrm{M}$ ), together with the primers for $\beta$-actin (concentration range: 0.015-0.04 $\mu \mathrm{M})$. The PCR conditions were: $95^{\circ} \mathrm{C}$ for 7 min and then 35 cycles at $95^{\circ} \mathrm{C}$ for $30 \mathrm{sec}, 60^{\circ} \mathrm{C}$ for 30 sec and $72^{\circ} \mathrm{C}$ for $55 \mathrm{sec}$ and a final extension at $72^{\circ} \mathrm{C}$ for $5 \mathrm{~min}$. The PCR products were separated on $1.6 \%$ agarose gel, visualized by ethidium bromide staining. Gel images were captured by a digital photocamera (UviDoc) and the intensity of the bands was analyzed with Quantity-One software (Bio-Rad, Segrate, Milan, Italy). A t-test for paired samples was used to compare normal mucosa and tumor expression as previously described [16].

\section{Array-comparative genomic hybridization}

A different set of ten samples of paired TUM-NM harvested from the same 14 rats was used to explore the presence of genomic aberrations in $\mathrm{DMH}$-induced adenocarcinomas. To this purpose, genomic DNA was extracted by the DNeasy Tissue kit (Qiagen) and each tumour was hybridized on Agilent Rat Genome CGH Microarray $2 \times 105 \mathrm{~K}$, following the Agilent protocol, using the corresponding normal mucosa as reference. The Rat CGH Agilent arrays contain 97,973 coding and noncoding sequences with an average probe spatial resolution of $19.1 \mathrm{~Kb}$ allowing high resolution analysis of the rat genome. Slides were scanned using the Genepix
4000B microarray scanner (Axon Instruments, Foster City, CA, USA). Image analysis and initial quality control were performed using Agilent Feature Extraction Software v9.5. Feature Extraction files were then loaded into CGH Analytics 3.5.14 software (Agilent Technologies, Palo Alto, CA, USA) and analyzed for aberration calls by selecting as follows: algorithm ADM-2, centralization on, fuzzy zero on, threshold at 6.0, aberration filter set at 5 for the minimum number of probes in region and at 0.24 for the minimum absolute average $\log$ ratio for region. The Derivative Log Ratio Spread (DLRS) for the ten hybridizations was in the range 0.110.24 . The Rat genome sequence used was the $\mathrm{Rn} 4$ version.

\section{Immunohistochemical analysis}

Tumour sections from 6 adenocarcinomas were processed for immunohistochemistry as described [11], using as primary antibody a rabbit polyclonal antibody against NFkB/p65 (Thermo Fisher Scientific, Fremont, CA) diluted 1:100 in PBS containing $1 \%$ bovine serum albumin and incubated for $1 \mathrm{~h}$ at room temperature (RT). The slides were processed with Biotinylated Goat Anti-Polyvalent as the secondary antibody (LAB Vision Corporation, CA, USA), and then weakly counterstained with Harris's hematoxylin [11]. Negative controls in which the primary antibody was omitted were performed in each experiment.

\section{Results}

The analyses described in this paper were carried out in colon cancers harvested from 14 rats induced with $\mathrm{DMH}$ as described in the Methods. The mean number of total tumours (both adenomas and cancers)/rat was $2.5 \pm 0.34(\mathrm{SD})$; adenomas/rat were $1.14 \pm 1.09$ while cancers/rat were $1.36 \pm 0.49$; all rats developed tumours. All the cancers analyzed $(n=19)$ were adenocarcinomas (Fig. 1D), except for one that was a mucinous adenocarcinoma (sample \#14). Two samples were graded as moderately differentiated (samples \#2 and \#14), while the remaining 17 samples were well differentiated cancers.

\section{Gene expression profile by microarray analysis}

Nine colon adenocarcinomas were hybridized on Agilent microarrays and each compared with its respective normal mucosa (NM). Eight out of nine of these samples passed the quality control step and were then analyzed as described in detail in the Methods section. Of the about 41,000 genes and transcripts present in the $4 \times$ $44 \mathrm{~K}$ Agilent Rat Whole Genome Expression slides, 27,329 probes passed the quality control step. The complete list of these 27,329 gene probes is provided as Additional file 2: Complete microarray gene expression 


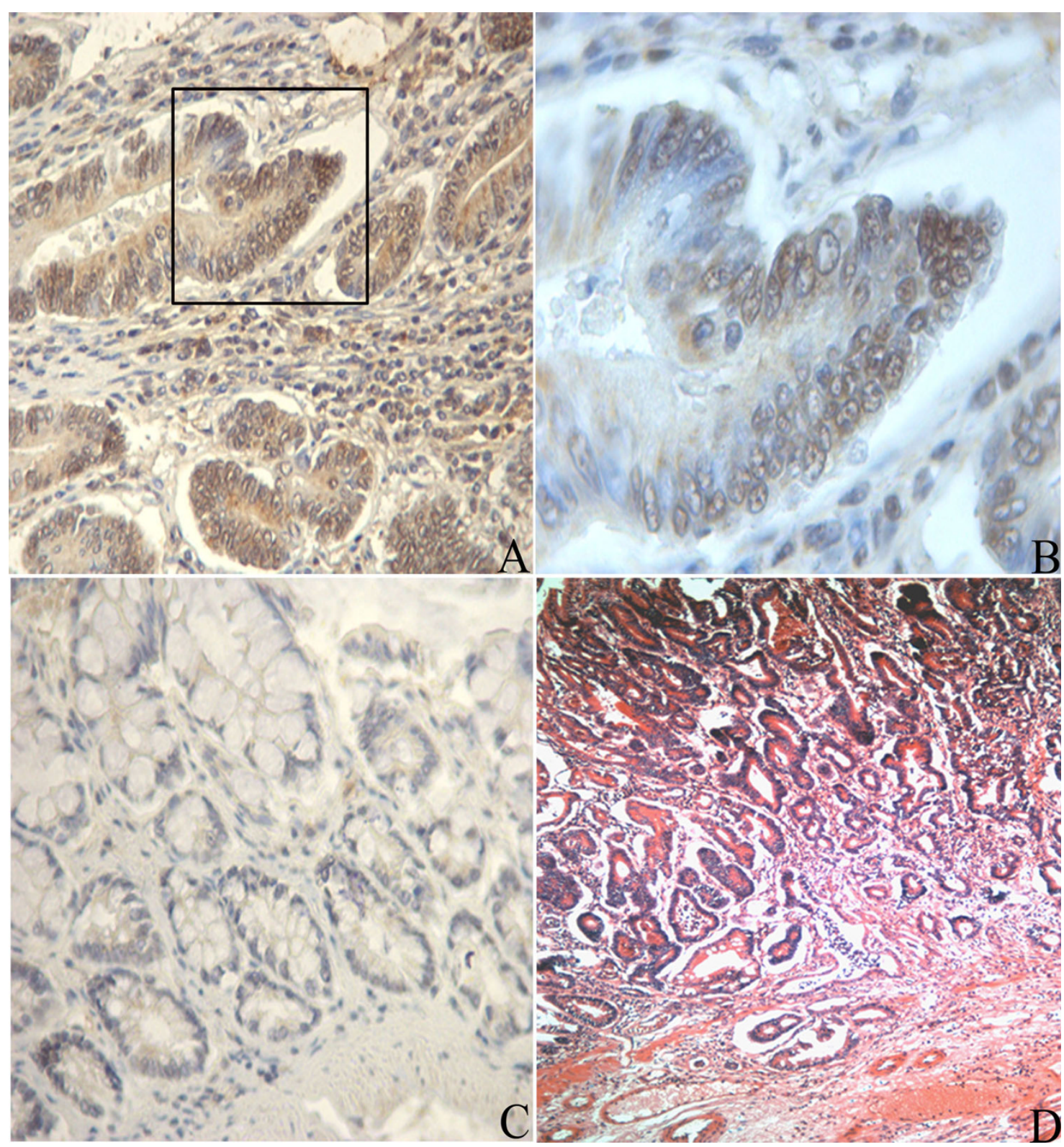

Figure 1 Immunohistochemistry for NFkB/p65 and histology in a DMH-induced cancer. Panel A: adenocarcinoma sample challenged with an antibody against NFkB/p65. Panel B: magnification of the inset in panel A; note that positive cells in the tumour show immunoreactivity in both the cytoplasm and the nucleus. Panel C: paired normal mucosa of the tumor challenged with the same antibody. Panel D: H\&E stained section of the same tumour. Original magnification in panels A and C: $\times 400$, panel B: $\times 1000$, panel D: $\times 100$.

data from the comparison between normal mucosa and adenocarcinomas. This list also comprises the 15,251 significantly up- or down-regulated gene probes as determined by statistical analysis (see the column with heading adjPVal).

Hierarchical clustering analysis of the eight array expression data $(\mathrm{n}=8)$ shows a homogenous expression profile among these samples (Additional file 3: Hierarchical clustering analysis of gene expression data).
Setting a filter to a fold change (FC) equal to \pm 10 , we found that $266(1 \%)$ and $566(2 \%)$ genes were significantly up- or down-regulated in tumours vs NM, respectively (see Additional file 2). Moreover, using a FC cut-off equal to $\pm 2,3724$ (13.6\%) and 3750 (13.7\%) genes were significantly up- and down-regulated in tumors, respectively (see Additional file 2). Table 1 shows the first 25 up-regulated genes in tumours; among these, we found Defcr4 (defensin-related cryptdin 4), Slc30a2 
Table $\mathbf{1}$ List of the first $\mathbf{2 5}$ genes up- and down-regulated in tumours.

\begin{tabular}{|c|c|c|}
\hline Gene name & Gene Description [Accession number] & FC \\
\hline \multicolumn{3}{|l|}{ Up-regulated } \\
\hline Defcr4 & Defensin related cryptdin 4 [NM_001013053] & 183.2 \\
\hline S/c30a2 & Solute carrier family 30 (zinc transporter), member 2 [NM_012890] & 71.7 \\
\hline Lum & Lumican [NM_031050] & 70.0 \\
\hline Mmp12 & Matrix metallopeptidase 12 [NM_053963] & 65.1 \\
\hline $\operatorname{lggc}$ & Immunoglobulin gamma2a constant region [DQ402472] & 58.8 \\
\hline Hoxd13_predicted & Homeo box D13 (predicted) [XM_221511] & 50.5 \\
\hline lgfbp5 & Insulin-like growth factor binding protein 5 [BC087030] & 48.4 \\
\hline CB548350 & Tenascin C [CB548350] & 47.0 \\
\hline Msr2_predicted & Macrophage scavenger receptor 2 (predicted) [XM_227485] & 45.7 \\
\hline Mx2 & Myxovirus (influenza virus) resistance 2 [NM_134350] & 43.9 \\
\hline Aldhia3 & Aldehyde dehydrogenase family 1, subfamily A3 [NM_153300] & 42.8 \\
\hline $\mathrm{CxCl} 2$ & Chemokine (C-X-C motif) ligand 2 [NM_053647] & 39.9 \\
\hline Mmp7 & Matrix metallopeptidase 7 [NM_012864] & 39.4 \\
\hline Nos2 & Nitric oxide synthase 2, inducible [NM_012611] & 38.1 \\
\hline$\$ 100 a 8$ & S100 calcium binding protein A8 (calgranulin A) [NM_053822] & 36.2 \\
\hline lgfbp7 & Insulin-like growth factor binding protein 7 [XM_214014] & 35.8 \\
\hline Col12a1 & PREDICTED: procollagen, type XII, alpha 1 [XM_243912] & 35.7 \\
\hline Plod2 & Procollagen lysine, 2-oxoglutarate 5-dioxygenase 2 [NM_175869] & 33.4 \\
\hline S100a9 & S100 calcium binding protein A9 (calgranulin B) [NM_053587] & 31.9 \\
\hline Ctgf & Connective tissue growth factor [NM_022266] & 31.5 \\
\hline Fn1 & Fibronectin 1 [NM_019143] & 31.4 \\
\hline T_predicted & T, brachyury homolog (mouse) (predicted) [XM_217890] & 30.0 \\
\hline Sparc & Secreted acidic cysteine rich glycoprotein [NM_012656] & 29.6 \\
\hline Cyp26b1 & Cytochrome P450, family 26, subfamily b, polypeptide 1 [NM_181087] & 29.4 \\
\hline Nkd1_predicted & Naked cuticle 1 homolog (Drosophila) (predicted) [XM_001066780] & 29.1 \\
\hline \multicolumn{3}{|l|}{ Down-regulated } \\
\hline S/c26a3 & Solute carrier family 26, member 3 [NM_053755] & -502.6 \\
\hline Mptx & Mucosal pentraxin [NM_001037642] & -376.5 \\
\hline Retnla & Resistin like alpha [NM_053333] & -166.9 \\
\hline Zg16 & Zymogen granule protein 16 [NM_134409] & -105.3 \\
\hline Clca3_predicted & Chloride channel calcium activated 3 (predicted) [XM_217689] & -99.1 \\
\hline Grap & GRB2-related adaptor protein [NM_001025749] & -95.2 \\
\hline Fabp 1 & Fatty acid binding protein 1, liver [NM_012556] & -94.7 \\
\hline Ceacam20_predicted & CEA-related cell adhesion molecule 20 (predicted) [XM_218430] & -92.8 \\
\hline Dpep 1 & Dipeptidase 1 (renal) [NM_053591] & -90.9 \\
\hline Pbp2 & Phosphatidylethanlomine binding protein 2 [XM_575702] & -90.4 \\
\hline B4 galt2_predicted & UDP-Gal:betaGIcNAc beta 1,4-galactosyltransferase, polypeptide 2 (predicted) [XM_242992] & -90.0 \\
\hline Apoal & Apolipoprotein A-I [NM_012738] & -80.6 \\
\hline Olr1611_predicted & Olfactory receptor 1611 (predicted) [XM_223954] & -80.5 \\
\hline Dmbt1 & PREDICTED: deleted in malignant brain tumours 1 (Dmbt1), [XM_577842] & -80.0 \\
\hline Muc2 & Mucin $2[$ U07615] & -78.7 \\
\hline Trpm5_predicted & Transient receptor potential cation channel, subfamily M, member 5 (predicted) [XM_344979] & -73.1 \\
\hline Chia & Rattus norvegicus chitinase, acidic [NM_207586] & -72.7 \\
\hline Kb15 & Type II keratin Kb15 [XM_345877] & -72.6 \\
\hline Gpr156 & G protein-coupled receptor 156 [NM_153295] & -71.8 \\
\hline Pdha2 & Pyruvate dehydrogenase E1 alpha 2 [NM_053994] & -71.3 \\
\hline Hspall_mapped & Heat shock 70 kD protein 1-like (mapped) [NM_212546] & -71.0 \\
\hline Pcdhb13 & PREDICTED: Protocadherin beta 13 [XM_001055698] & -71.0 \\
\hline Pcsk4 & Proprotein convertase subtilisin/kexin type 4 [NM_133559] & -70.4 \\
\hline Masp 1 & Mannan-binding lectin serine peptidase 1 [NM_022257] & -70.4 \\
\hline Clall_predicted & Complement component 1, q subcomponent-like 1 (predicted) [XM_343971] & -70.3 \\
\hline
\end{tabular}


(a solute carrier specific for zinc transport), Lum (lumican, a member of a small leucine-rich proteoglycan family), Mmp12 (matrix metallopeptidase 12), Igfbp5 (insulin growth factor binding protein 5), Mmp7 (matrix metallopeptidase 7), Nos 2 (nitric oxide synthase 2, inducible), S100A8 (S100 calcium binding protein A8 (calgranulin A)) and S100A9 (S100 calcium binding protein A9 (calgranulin B)). Among the most down-regulated genes (Table 1), we found Slc26a3 (solute carrier family 26, member 3, also known as down-regulated in adenoma (Dra)), Mptx (mucosal pentraxin), Retnla (resistin like$\alpha$ ), Muc2 (mucin 2). For a selected group of genes, the results obtained with microarray analysis were confirmed by semi-quantitative RT-PCR. These were Defcr4, S100A9, Igfbp5, Slc30a2 and Lgr5 (leucine-rich repeat containing $\mathrm{G}$ protein coupled receptor 5 ) which were upregulated and Mptx, Slc26a3, Retnla, Muc2 and Hpgd (hydroxyprostaglandin dehydrogenase 15) which were down-regulated in tumours (Fig. 2).

To understand whether specific biological pathways or functional groups of genes were differentially affected in tumours, we analyzed our microarray data set using the Gen MaPP/MappFinder software tool. The results of this analysis showed that 17 pathways were significantly up-regulated in tumours, while 10 were down-regulated (Table 2). The list of genes present in these significantly up- or down-regulated pathways is shown in Additional files 4 and 5 (Additional file 4: List of the genes belonging to the significantly up-regulated pathways; Additional file 5: List of the genes belonging to the significantly down-regulated pathways). Among the upregulated pathways we found those related to cell cycle, to RNA and protein metabolism, to extracellular matrix remodeling.

Moreover, since the results of this analysis also pointed out an up-regulation of the inflammatory processes (inflammatory response pathway, TNF $\alpha-N F k B$, complement activation), we further investigated the involvement of the NFkB pathway, determining in six adenocarcinomas the expression of RelA (p65) with immunohistochemistry. The results (Fig.1, panels A-C) showed that p65, a key member of the NFkB pathway, was highly expressed in the tumours compared to normal mucosa.

Among the pathways and grouping of functional genes down-regulated in tumors (Table 2) we found those

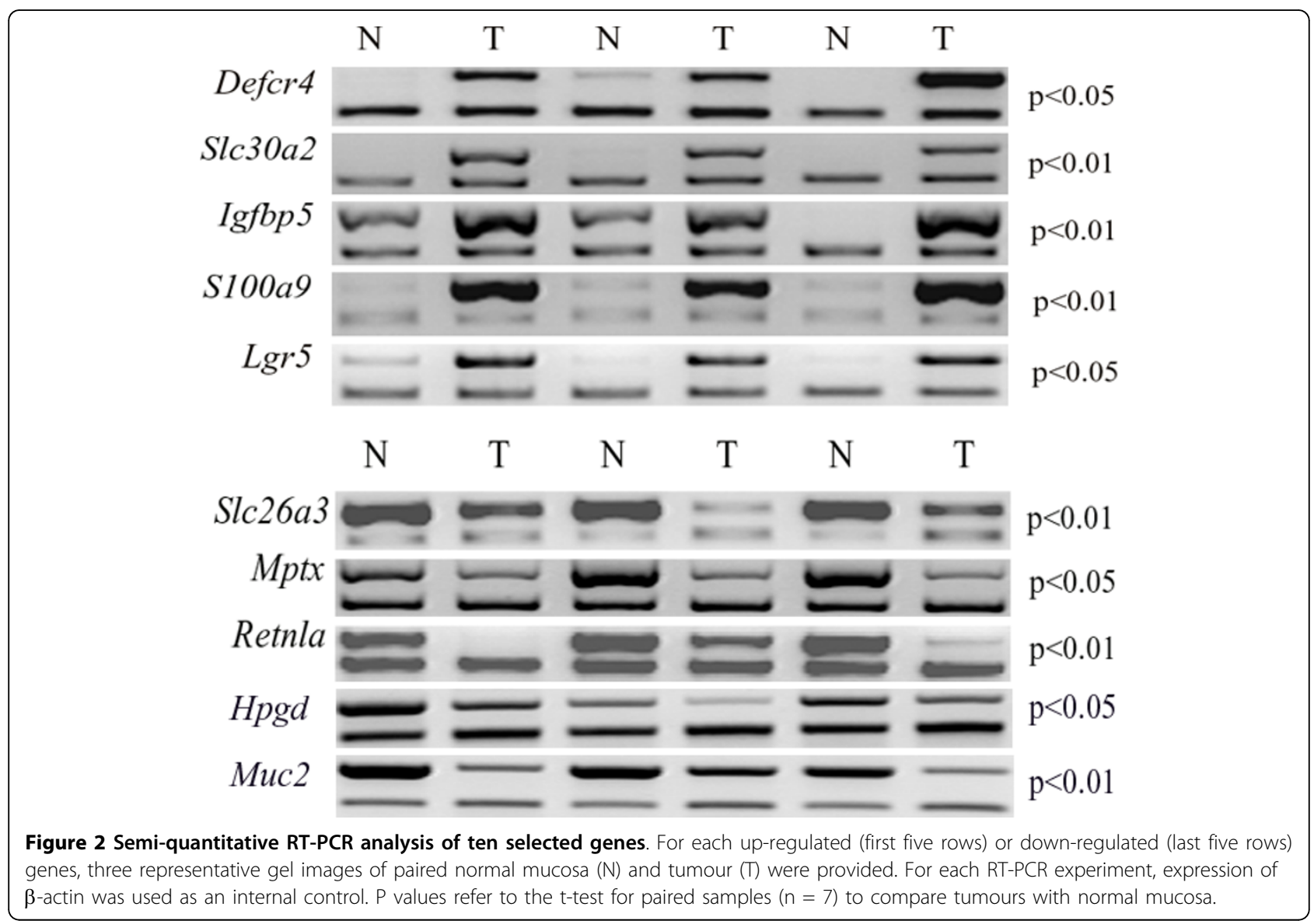


Table 2 Pathways or functional groups of genes differentially expressed in tumours by GenMapp/MappFinder analysis*.

\begin{tabular}{|c|c|c|c|c|}
\hline MAPP Name & Number Changed & Number Measured & Number On MAPP & Z Score \\
\hline \multicolumn{5}{|l|}{ Up-regulated pathways or functional group of genes } \\
\hline Rn_DNA_replication_Reactome & 17 & 22 & 40 & 3.289 \\
\hline Rn_Matrix_Metalloproteinases & 12 & 13 & 28 & 3.621 \\
\hline Rn_TNF-alpha-NF-kB_NetPath_9 & 69 & 117 & 159 & 3.648 \\
\hline Rn_G1_to_S_cell_cycle_Reactome & 29 & 40 & 69 & 3.838 \\
\hline Rn_mRNA_processing_Reactome & 44 & 66 & 125 & 3.988 \\
\hline Rn_Translation_Factors & 24 & 29 & 40 & 4.383 \\
\hline Rn_Ribosomal_Proteins & 65 & 74 & 81 & 7.979 \\
\hline Rn_Cell_cycle_KEGG & 32 & 49 & 80 & 3.227 \\
\hline Rn_RNA_transcription_Reactome & 15 & 19 & 41 & 3.202 \\
\hline Rn_TGF_Beta_Signaling_Pathway & 27 & 39 & 45 & 3.372 \\
\hline Rn_Inflammatory_Response_Pathway & 16 & 22 & 40 & 2.855 \\
\hline Rn_Proteasome_Degradation & 27 & 42 & 53 & 2.848 \\
\hline Rn_Alpha6-Beta4-Integrin_NetPath_1 & 29 & 47 & 64 & 2.654 \\
\hline Rn_B_Cell_Receptor_NetPath_12 & 61 & 112 & 146 & 2.573 \\
\hline Rn_Signaling_of_Hepatocyte_Growth_Factor_Receptor_Biocarta & 18 & 27 & 33 & 2.527 \\
\hline Rn_Nucleotide_Metabolism & 10 & 14 & 17 & 2.175 \\
\hline Rn_Complement_Activation_Classical & 7 & 9 & 14 & 2.127 \\
\hline \multicolumn{5}{|l|}{ Down-regulated pathways or functional group of genes } \\
\hline Rn_Nuclear_Receptors & 16 & 26 & 37 & 3.564 \\
\hline Rn_Unsaturated_Fatty_Acid_Beta_Oxidation_BiGCaT & 6 & 6 & 6 & 3.766 \\
\hline Rn_Electron_Transport_Chain & 26 & 44 & 58 & 4.298 \\
\hline Rn_Nuclear_receptors_in_lipid_metabolism_and_toxicity & 13 & 19 & 33 & 3.700 \\
\hline Rn_Fatty_Acid_Beta_Oxidation_2_BiGCaT & 5 & 6 & 6 & 2.873 \\
\hline Rn_Krebs-TCA_Cycle & 12 & 23 & 26 & 2.362 \\
\hline Rn_Irinotecan_pathway_PharmGKB & 5 & 6 & 12 & 2.873 \\
\hline Rn_Peptide_GPCRs & 15 & 31 & 62 & 2.283 \\
\hline Rn_Calcium_regulation_in_cardiac_cells & 41 & 102 & 150 & 2.360 \\
\hline Rn_Glucocorticoid_Mineralocorticoid_Metabolism & 5 & 7 & 9 & 2.414 \\
\hline
\end{tabular}

* Significantly enriched pathways ( $z$-score $>2$ ) are listed. The different columns show the number of genes differentially expressed compared with normal mucosa, the number of genes analyzed and the number of genes listed in each map (http://www.genmapp.org; University of California at San Francisco, San Francisco, CA, USA)

related to cellular metabolism (fatty acid beta-oxidation, Krebs-tricarboxylic acid cycle and electron transport chain) and nuclear receptors.

\section{Genomic alterations by a-CGH}

An additional set of ten colon adenocarcinomas harvested from the same rats were analyzed by a-CGH, comparing each tumour sample with its respective normal mucosa (NM). All the hybridized arrays passed the quality control step and were then analyzed by the CGH Analytics 3.5 software (Agilent Technologies) for detection of chromosomal aberrations. In the 10 tumors analyzed, a total of 6 alterations were observed in four tumours (Table 3). Four of these 6 aberrations were amplifications (length of the amplified regions ranged from 67 to $2135 \mathrm{~kb}$ ) and two were deletions (672 kb and $1362 \mathrm{~kb}$, respectively). Two tumours (samples \#3 and \#5) showed two aberrations each (two amplifications in tumour \#3 and one amplification plus a deletion in tumour \#5), while the remaining two samples had only one aberration each.

The genomic aberrations were located in a region of chromosome 1, amplified in one tumor containing Pcsk6, coding for a protease belonging to the pro-protein convertase family. The same tumour carrying this amplification also carried a long amplification on chromosome 7 with more than forty genes mapping in this region (Table 3). Contrary to the long amplification of chromosome 7 , the deletion on the same chromosome carried by a different tumour was short, with only two genes (Nudt4 and Ac1-114) mapping in this region. Notably, in tumour sample \#9, we observed an interstitial deletion of $1.36 \mathrm{Mb}$ on chromosome 18 encompassing the Apc (Adenomatous polyposis coli) gene as well as other genes such as Catna1 (coding for $\beta$-catenin) (Table 3 and Fig. 3). 
Table 3 Summary of the chromosomal aberrations found in adenocarcinomas from DMH-induced rats.

\begin{tabular}{|c|c|c|c|c|}
\hline Tumour & Aberration & Chromosome & $\begin{array}{l}\text { Aberration } \\
\text { length }(\mathrm{kb})\end{array}$ & Genes in the aberrant region \\
\hline \multirow[t]{2}{*}{$\# 3$} & Amplification & $1 \mathrm{q} 22$ & 109.8 & Pcsk \\
\hline & Amplification & $7 q 11$ & 2135.3 & $\begin{array}{l}\text { Sirt6, Tle2, Aes, Gna11, Gna15, Ncln, NF1-C2, Tbxa2r, Pip5k1c, Apba3, Matk, Atcay_predicted, } \\
\text { Dapk3, Zbtb7a, Map2k2, Creb313, Thop1, Sgta, Slc39a3, Gng7, Gadd45b, Tmprss9_predicted, } \\
\text { RGD1308556, Sf3a2, Mknk2, Csnk1 g2, Scamp4, RGD1359682, Tcfe2a, Reep6, Pcsk4, Dazap1, } \\
\text { Cirbp, Abca7, Grin3b, Prtn3_predicted,Prg-2,Ptbp1,Palm, Fst13, Rnf126, Hcn2, Bsg, }\end{array}$ \\
\hline \multirow[t]{2}{*}{ \# 5} & Deletion & $7 q 13$ & 671.9 & Nudt4, Ac1-114 \\
\hline & Amplification & $2 q 23$ & 66.9 & LOC360689 \\
\hline \# 6 & Amplification & $15 q 22$ & 189.4 & Unknown \\
\hline \# 9 & Deletion & $18 \mathrm{p} 11-12$ & 1362.1 & Apc, Brd8, Gfra3, Egr1, Etf1, Catna1, Sil1 \\
\hline
\end{tabular}

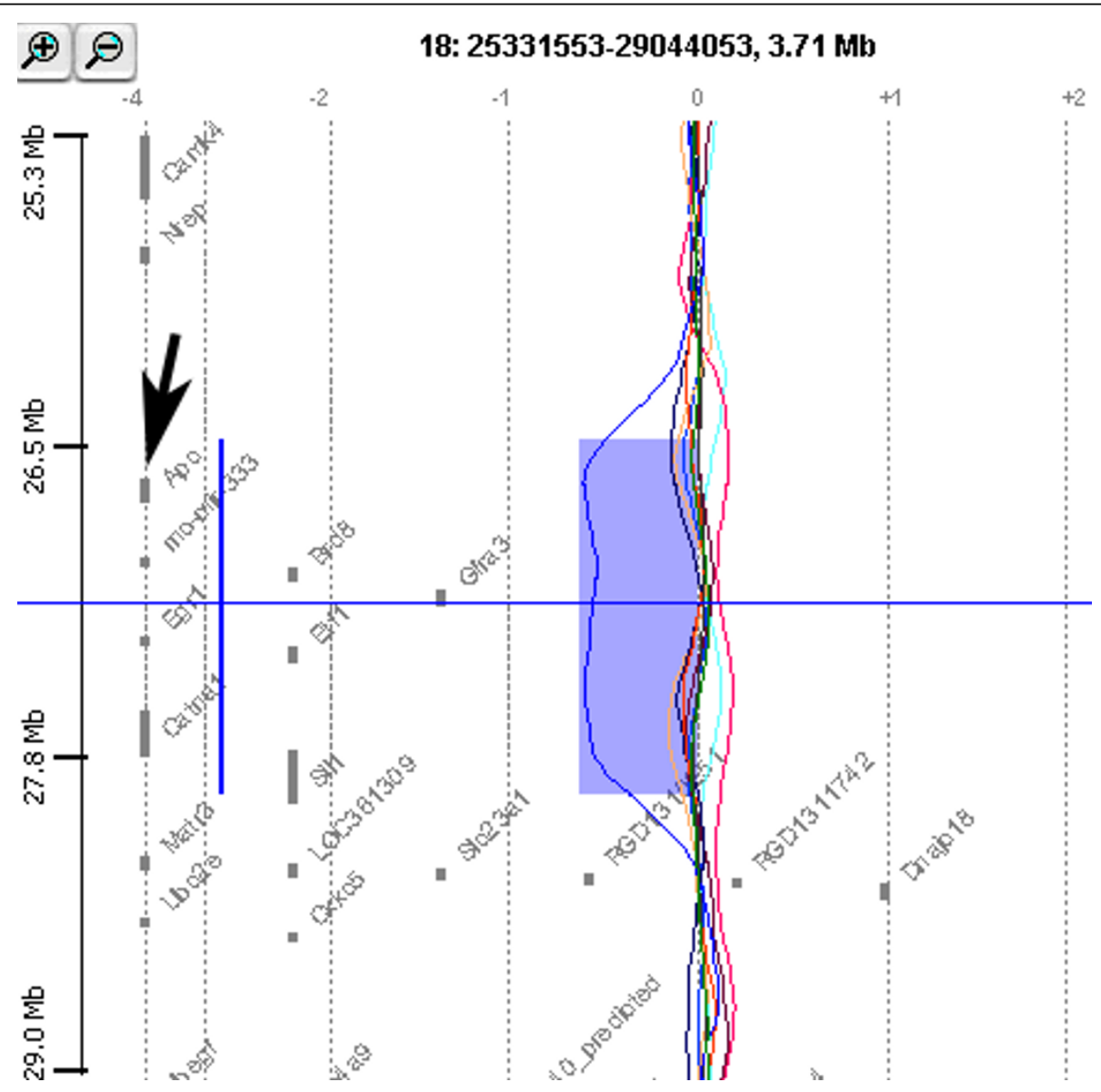

Figure $3 \mathrm{CGH}$ analytics chromosome view of a region of chromosome 18 of all tumor samples analyzed. Colored curves represent Log 2 ratio values for all nucleotide probes plotted as a function of their chromosomal position for each tumor sample. Thick straight vertical blue line and blue shaded area point out a deletion present in sample \#9. The black arrow indicates the Apc gene position.

\section{Discussion}

This is the first report describing variations in gene expression and genomic alterations in $\mathrm{DMH}$-induced rat colon adenocarcinomas using microarray technologies. We found that many transcripts were differentially expressed in colon tumors, 7400 of them being differentially expressed in tumours with a FC $\geq 2$ [3724 (13.6\%) and $3750(13.7 \%)$ up-regulated or down-regulated in tumours].

The most up-regulated gene was Defcr4, also known as enteric defensin $\alpha 5$, belonging to the family of the $\alpha$ defensin antimicrobial peptides secreted by Paneth cells [17]. Other markers of Paneth cells such as defensin alpha $6($ Defa6; FC = 18.7), matrix metallopeptidase 
7 (Mmp7), lysozyme $(L y z ; \mathrm{FC}=13.1)$, secretory phospholipaseA2 (Pla2 g2a; FC = 20), were also up-regulated in our samples, suggesting that these cells are a cellular component of colon tumours, in agreement with previous reports [17-19]. Although it has been suggested that the presence of Paneth cells in colon cancer is a fortuitous consequence of the Wnt pathway activation $[17,20]$, it is interesting to note that $M m p 7$ up-regulation, as observed in our samples, has been correlated with metastasis and apoptosis resistance in cancer [21]. Besides $M m p 7$, other metalloproteinases (MMPs) involved in the degradation of extracellular matrix in the late phases of carcinogenesis were up-regulated in our samples $(\mathrm{Mmp3}, 9,10,12$ and $14 ; \mathrm{FC}=4.3,18.1$, 13.1, 65.1, 3.2, respectively) (see also Additional file 2) [18], a result reinforced by the significant up-regulation of the MMP pathway pointed out by GenMapp analysis. Linked to MMPs in the process of invasion, we also found up-regulation of genes involved in the urokinasetype plasminogen activator system such as urokinaseplasminogen activator $\mathrm{u}-\mathrm{PA}(\mathrm{Plau}$ in rat; $\mathrm{FC}=9.6)$, $\mathrm{u}$-PA receptor (Plaur; $\mathrm{FC}=2$ ) and plasminogen (Plg; FC = 13.6) (see Additional file 2) [22]. Interestingly, it has also been suggested that u-PA might catalyze the activation of the mesenchymal-derived cytokine hepatocyte growth factor/Scatter Factor (HGF/SF), thus facilitating invasiveness [22,23], an observation in line with the activation of HGF signaling in our tumours, as pointed out by the GenMapp analysis.

Slc30a2, the second most up-regulated gene in our set of colon adenocarcinomas, codes for the protein Znt2 which has been reported to promote zinc efflux into intracellular vesicles when $\mathrm{Zn}$ concentration rises in the cell [24]. Accordingly, a previous study showed that $\mathrm{Zn}$ concentration was higher in rat colon tumours than in normal mucosa [25].

The Lum gene, coding for the protein Lumican, is the third most expressed gene in our set of tumours (Table 1). Lumican plays an important role in collagen fibrillogenesis and its over-expression has been reported in human colorectal cancer [26]. Another dramatically up-regulated gene in our samples is Igfbp5 (Insulin-like growth factor-binding protein 5) (Table 1), a component of the IGF axis [27], implicated in colon carcinogenesis with contradictory results $[28,29]$. Indeed, while $I g f b p 5$ is up regulated in adenomas from $\mathrm{Apc}^{\mathrm{Min} /+}$ mice, it moves in the opposite direction in human colorectal cancers and cancer cell lines [28]. It has also been shown that IGFBP5 can be cleaved by MMP7 forming IGF-II which in turn can act as a growth factor for colonic myofibroblasts [29], suggesting an important role for IGFBP5 and MMP-7 in the tumoural epithelial-mesenchymal transition. Recent evidence also indicates that $\operatorname{Igfbp} 5$ may act as a tumour suppressor by inhibiting angiogenesis [30]. These results suggest the need to further investigate the role of $I g f b p 5$ in colon cancers.

Among the most up-regulated genes we also found Nos2 (Table 1) coding for the pro-inflammatory enzyme inducible nitric oxide synthase (i-NOS). Many reports document high i-NOS activity in colorectal cancers [31,32]; recently, we also reported that $\mathrm{DMH}$-induced colorectal tumours have high i-NOS expression [33]. Interestingly, $S 100 A 8$ and $S 100 A 9$, whose products form the heterocomplex calprotectin, are strongly up-regulated in our study (Table 1), in agreement with reports on inflammation-associated cancer and in human colorectal carcinomas [34,35]. Accordingly, we also observed an upregulation of genes involved in prostaglandin synthesis, such as cyclooxygenase 1 and 2 (Ptgs 1 and Ptgs2; FC = 5.4 for both genes, see Additional file 2) and prostaglandin E synthase (Ptges; $F C=2.2$ ) associated with strong down-regulation of the gene for the enzyme degrading prostaglandins (15-hydroxyprostaglandin dehydrogenase, Hpgd; FC = -29), as demonstrated in both the array and RT-PCR experiments and in agreement with previous reports showing a down-regulation of this gene in colon carcinogenesis [36]. Moreover, GenMapp analysis pointed out that the TNF $\alpha-N F-k B$ pathway was upregulated in our samples, as also demonstrated by the over-expression of p65 (RelA) observed with both immunohistochemistry (Fig.1, panels A-C) and array technique (FC of RelA: 2.2, see additional file 2). All these data confirm that DMH-induced tumours show activation of inflammatory process pathways, as documented in rats and human colon cancer [32,33,37].

Aberrant activation of the Wnt signaling has been demonstrated in both experimental and human carcinogenesis [38]. Accordingly, many Wnt-target genes were up-regulated in our samples (Ccnd2 $(\mathrm{FC}=5.9)$, Lef1 $(\mathrm{FC}=21.5), M m p 7, A x i n 2(\mathrm{FC}=3.9), C D 44(\mathrm{FC}=3.4)$, Bmp4 $(\mathrm{FC}=5.1), D k k 3(\mathrm{FC}=14.3)$, Sox9 $(\mathrm{FC}=2.9)$, Fn1 (FC = 31.4), Mmp9 (FC = 18.1), Stra6 (FC = 21.3), Ptgs2 (FC = 5.4), Postn $(\mathrm{FC}=11.8)$, Sfrp $2(\mathrm{FC}=6.3))$ [39] (see also Additional file 2). Notably, Lgr5, a marker of stem cells in colon epithelium [18] was also up-regulated in the arrays $(\mathrm{FC}=10)$ as well as in RT-PCR experiments, demonstrating that cells presenting this stem marker are over-represented not only in Min mice intestinal tumours and human colon cancers [40,41], but also in $\mathrm{DMH}$-induced colonic tumors.

As expected, we also found an up-regulation of pathways related to nucleotide metabolism, DNA replication, cytoplasmic ribosomal protein, translation factors, proteasome degradation, mRNA processing and cell cycle (Table 2).

On the contrary, the up-regulation of the TGF- $\beta$ pathway in our samples was somewhat unexpected since 
previous findings in colon cancers showed inactivation of TGF- $\beta$ signaling [42-44]. In our samples the genes coding for the ligand $T g f b 1$ ( $\mathrm{FC}=5.7)$, the receptors Tgfrb1 $(\mathrm{FC}=2.6)$ and Tgfrb2 $(\mathrm{FC}=5.5)$ as well as Smad2 $(\mathrm{FC}=2.9)$ and Smad4 $(\mathrm{FC}=2.4)$ were up-regulated, although not Smad3 (FC = -2.3) which was downregulated. It is interesting to note that although TGF- $\beta$ is a potent inhibitor of normal colonic epithelial cells, it can also promote the survival, invasion and metastasis of colorectal cancer cells, thereby acting as an oncogene, a paradoxical role which could explain our results $[45,46]$.

Slc26a3, coding for a $\mathrm{Cl}(-) / \mathrm{HCO}(3)(-)$ exchanger, is the most down-regulated gene in this report. Although genetic studies linked mutations in the homologous human gene (SLC26A3) to congenital chloride-losing diarrhea, it is interesting to note that $S l c 26 a 3$ is also known with the alias "down-regulated in adenoma" (Dra), since it was first identified as a gene strongly down-regulated in colon adenomas and adenocarcinomas $[47,48]$. Its deficiency has been associated with an increase in cellular proliferation [48], a feature that could partly contribute to tumour development also in our samples. Mptx, the gene coding for mucosal rat pentraxin, is also strongly down-regulated in the present study. Mptx was first described as the most down-regulated gene in the colonic mucosa of rats fed dietary heme and, since it has been suggested to play a role in the clearance of dying cells, its down-regulation could lead to a reduced apoptosis ability, another characteristic of tumour cells [49]. Retlna (resistin-like molecule $\alpha$ ), which is also down-regulated in our samples (Table 1 and Fig. 2), belongs to a family of resistin-like molecules implicated in metabolism, energy balance and intestinal inflammation [50].

We also observed a strong down-regulation of the Muc2 gene, coding for Muc2, the most abundant mucin secreted by normal colonocytes, in agreement with experimental and clinical reports documenting defective mucin production in colorectal cancer [51,52].

Significantly down-regulated pathways were processes such as Krebs-TCA-cycle, electron transport chain, and fatty acid beta-oxidation (Table 2), in agreement with many previous observations showing a metabolic reprogramming of the cancer cell favoring glycolysis even in the presence of oxygen [53].

It has also to be noted that our rats were fed a highfat diet containing $23 \%$ corn oil as a source of fat, a diet currently used in our laboratory since it closely mimics the high-fat diet typical of western countries with populations having a high incidence of colon cancer. Thus one could wonder whether the same results would be observed also in animals fed a low-fat diet. However, since in our experiments we compared tumours with their paired normal mucosa, it is not possible to infer the influence of diet on gene expression profile in tumours. In fact, to carefully address this issue, one would have to perform an additional experiment comparing the tumour profile from low-fat diet rats with that from high-fat diet rats.

In the present study we also evaluated genomic alterations with a-CGH analysis in a different set of tumours harvested from the same rats. This is, to our knowledge, the first attempt to highlight genomic aberrations in $\mathrm{DMH}$-induced colonic tumours in the rat by means of high resolution a-CGH.

Our results show that genomic aberrations are relatively infrequent, with $40 \%$ of tumours showing only one or two aberrations (i.e. amplification or deletion), while the remaining $60 \%$ show a stable genome. The detected alterations spanned from 66 to $2135 \mathrm{~kb}$ and in no case did we observe gains or losses of whole chromosomes. The relatively low level of genomic alterations in this study is in agreement with previous reports on tumours from Min mice and AOM-treated A/J mice $[8,54]$. In a previous study from our laboratory, we reported frequent genomic alterations in AOM-induced colon tumours using RAPD analysis [7]; this discrepancy might be due to the fact that high-resolution a-CGH, at variance with RAPD, does not detect small alterations (such as single base mutations), which could be frequent in this model.

Notably, one of the aberrations found in the present study was a deletion on chromosome 18 , spanning a $1362 \mathrm{~kb}$ region containing the $A p c$ gene, a key gene in colon cancer [38]. Previously, we demonstrated that $\mathrm{DMH}$-induced colon cancers, beside mutations in Ctnnb1 (coding for $\beta$-catenin) and Kras, carry singlenucleotide mutations in $A p c$ with a frequency of about $30 \%$ [2]. Therefore, the occurrence of an interstitial deletion encompassing this gene could be a further mechanism of $A p c$ inactivation in colon carcinogenesis. Accordingly, allelic loss of one $A P C$ gene copy without detectable $A P C$ mutation has been reported in human colorectal tumours [55]. It is also interesting to note that among the genes mapping in the region deleted in this sample, we found Catna1 (coding for $\beta$-catenin). Unlike $\beta$-catenin, the contribution of $\alpha$-catenin to colorectal carcinogenesis is controversial [56]. In fact some reports suggest that $\alpha$-catenin is essential for tumour formation [56], while others suggest that $\alpha$ catenin plays a tumour-suppressive role in the late stages of colorectal carcinogenesis [57,58]. Notably all the genes deleted on chromosome 18 (including Apc and Catna1), are synthenic with their human homologues genes (i.e. they are also close to each other in the human genome, all of them mapping on the short arm of chromosome 5). 


\section{Conclusions}

In conclusion, we have used genome-wide technologies to study the gene expression profile and genomic alterations in DMH-induced colon cancers, for which no information was previously available. Our results show complex gene expression alterations in adenocarcinomas encompassing many altered pathways such as those linked to inflammation, matrix metalloproteases, cell proliferation and metabolism. While a-CGH analysis showed a low degree of genomic imbalance in these tumours, it is interesting to note that one of the alterations found regards $A p c$, a key gene in colorectal carcinogenesis. The fact that many of the alterations described in this study are documented in human colon tumours confirms the relevance of DMH-induced cancers as a powerful tool for the study of colon carcinogenesis and chemoprevention. Moreover, the results of this study encompassing the characterization of genomic alterations in colon adenocarcinomas may serve as the basis for investigations of the derangements occurring in the early phases of colon carcinogenesis, which are easily analyzed using this model.

\section{Additional file 1: List of the primers used in the RT-PCR experiments. The file provides the sequences of the primers used for reverse-transcriptase-PCR experiments and the GenBank accession number for each gene.}

Additional file 2: Complete microarray gene expression data from the comparison between normal colon mucosa and adenocarcinomas. The file provides the complete list of the 27,329 probes passing the quality control step as described in the methods. For each probe, the Agilent probe name, gene name, gene identifier, EntrezGene ID http://www.ncbi.nlm.nih.gov/gene, $\log _{10}$ fold change (FC), FC and adjusted $\mathrm{P}$ value is reported. The fold changes are means of at least 4 out of 8 colon cancers. AdjPval $<0.05$ identifies genes differentially expressed in cancers compared to the corresponding NM.

Additional file 3: Hierarchical cluster analysis of gene expression data. Hierarchical cluster analysis of gene expression data from the 8 DMH-induced tumours (samples \# 11-18) compared to the corresponding normal colon mucosa. The analysis was performed on all genes which passed the quality control step present in $100 \%$ of the experiments.

Additional file 4: List of the genes belonging to the significantly up-regulated pathways. List of the genes (EntrezGene ID: http://www. ncbi.nlm.nih.gov/gene) belonging to the significantly up-regulated pathways shown in Table 2.

Additional file 5: List of the genes belonging to the significantly down-regulated pathways. List of the genes (EntrezGene ID: http:// www.ncbi.nlm.nih.gov/gene) belonging to the significantly downregulated pathways shown in Table 2 .

\section{Acknowledgements}

Supported by Fondo Ateneo ex-60\% of the University of Florence, European Network of Excellence in Nutrigenomics, NuGO (FOOD-CT-2004-506360), WCRF NL (World Cancer Research Fund, the Netherlands) and AICR (American Institute for Cancer Research). We thank Maddalena Salvadori for expert technical assistance and Mary Forrest for English revision. Data on the experiments described in the paper have been loaded into http://www.ebi.ac.uk/microarray-as/aer/login, as follows:
Experiment name: Genomic alterations in colonic tumours induced by $\mathrm{DMH}$ in rats

ArrayExpress accession: E-MEXP-2487

Specified release date: 2010-12-04 (YYYY-MM-DD)

Reviewer's user account:

Username: Reviewer_E-MEXP-2487

Password: 1260974960274

Experiment name: Gene expression profile of colonic tumours DMH-induced in rats

ArrayExpress accession: E-MEXP-2471

Specified release date: 2010-11-30

Reviewer's user account:

Username: Reviewer_E-MEXP-2471

Password: 1259853432380

\section{Author details}

${ }^{1}$ Department of Pharmacology, University of Florence, 6 Viale Pieraccini, 50139 Florence, Italy. ${ }^{2}$ Department of Pathology, General Hospital of PratoAzienda Sanitaria Locale 4, Prato, Italy.

\section{Authors' contributions}

GC and APF conceived and designed the work. APF carried out the carcinogenesis experiment, DNA and RNA extraction, RT-PCR validation experiments, a-CGH analysis by $\mathrm{CGH}$ Analytics software and drafted the manuscript. $\mathrm{CL}$ did the microarray (gene expression) and a-CGH

hybridizations, functional analysis by GenMapp/Mapp Finder software and a$\mathrm{CGH}$ analysis by $\mathrm{CGH}$ Analytics software. ST carried out the statistical analysis of microarray (gene expression) data. PD critically revised the manuscript and gave final approval of the version to be published. GC carried out the carcinogenesis experiment, drafted the manuscript and gave the main contribution to the interpretation of data. All authors read and approved the final manuscript.

\section{Competing interests}

The authors declare that they have no competing interests.

Received: 18 December 2009 Accepted: 11 May 2010

Published: 11 May 2010

\section{References}

1. Center MM, Jemal A, Ward E: International trends in colorectal cancer incidence rates. Cancer Epidemiol Biomarkers Prev 2009, 18:1688-94.

2. Femia AP, Caderni G: Rodent models of colon carcinogenesis for the study of chemopreventive activity of natural products. Planta Med 2008, 74:1602-7.

3. Corpet DE, Pierre F: How good are rodent models of carcinogenesis in predicting efficacy in humans? A systematic review and meta-analysis of colon chemoprevention in rats, mice and men. Eur J Cancer 2005, 4:1911-22

4. Cardoso J, Boer J, Morreau H, Fodde R: Expression and genomic profiling of colorectal cancer. Biochim Biophys Acta 2007, 1775:103-37.

5. Nambiar PR, Nakanishi M, Gupta R, Cheung E, Firouzi A, Ma XJ, Flynn C, Dong M, Guda K, Levine J, Raja R, Achenie L, Rosenberg DW: Genetic signatures of high- and low-risk aberrant crypt foci in a mouse model of sporadic colon cancer. Cancer Res 2004, 64:6394-401.

6. Kaiser S, Park YK, Franklin JL, Halberg RB, Yu M, Jessen WJ, Freudenberg J, Chen $X$, Haigis $K$, Jegga AG, Kong $S$, Sakthivel B, Xu H, Reichling T, Azhar M, Boivin GP, Roberts RB, Bissahoyo AC, Gonzales F, Bloom GC, Eschrich S, Carter SL, Aronow JE, Kleimeyer J, Kleimeyer M, Ramaswamy V, Settle SH, Boone B, Levy S, Graff JM, Doetschman T, Groden J, Dove WF, Threadgill DW, Yeatman TJ, Coffey RJ Jr, Aronow BJ: Transcriptional recapitulation and subversion of embryonic colon development by mouse colon tumour models and human colon cancer. Genome Biol 2007, 8:R131.

7. Luceri C, De Filippo C, Caderni G, Gambacciani L, Salvadori M, Giannini A, Dolara P: Detection of somatic DNA alterations in azoxymethaneinduced F344 rat colon tumours by random amplified polymorphic DNA analysis. Carcinogenesis 2000, 21:1753-6.

8. Guda K, Upender MB, Belinsky G, Flynn C, Nakanishi M, Marino JN, Ried T, Rosenberg DW: Carcinogen-induced colon tumours in mice are 
chromosomally stable and are characterized by low-level microsatellite instability. Oncogene 2004, 23:3813-21.

9. Femia AP, Caderni G, Bottini C, Salvadori M, Dolara P, Tessitore L: Mucindepleted foci are modulated by dietary treatments and show deregulation of proliferative activity in carcinogen-treated rodents. Int $\mathrm{J}$ Cancer 2007, 120:2301-5.

10. European Community: European community regulations on the care and use of laboratory animals. Law 86/609/EC 1986.

11. Femia AP, Luceri C, Dolara P, Giannini A, Biggeri A, Salvadori M, Clune Y, Collins KJ, Paglierani M, Caderni G: Antitumourigenic activity of the prebiotic inulin enriched with oligofructose in combination with the probiotics Lactobacillus rhamnosus and Bifidobacterium lactis on azoxymethane-induced colon carcinogenesis in rats. Carcinogenesis 2002, 23:1953-60.

12. Lodovici M, Luceri C, De Filippo C, Romualdi C, Bambi F, Dolara P: Smokers and passive smokers gene expression profiles: correlation with the DNA oxidation damage. Free Radic Biol Med 2007, 43:415-22.

13. Castagnini C, Luceri C, Toti S, Bigagli E, Caderni G, Femia AP, Giovannelli L, Lodovici M, Pitozzi V, Salvadori M, Messerini L, Martin R, Zoetendal EG, Gaj S, Eijssen L, Evelo CT, Renard CM, Baron A, Dolara P: Reduction of colonic inflammation in HLA-B27 transgenic rats by feeding Marie Ménard apples, rich in polyphenols. Br J Nutr 2009, 22:1-9.

14. Smyth GK: Linear Models and Empirical Bayes Methods for Assessing Differential Expression in Microarray Experiments. Statistical Applications in Genetics and Molecular Biology 2004, 3(1), Article 3.

15. Gene Map Annotator and Pathway Profiler Version 2.1. [http://www. genmapp.org].

16. Luceri C, Caderni G, Sanna A, Dolara P: Red wine and black tea polyphenols modulate the expression of cycloxygenase-2, inducible nitric oxide synthase and glutathione-related enzymes in azoxymethaneinduced F344 rat colon tumours. J Nutr 2002, 132:1376-9.

17. Van Es JH, Jay P, Gregorieff A, van Gijn ME, Jonkheer S, Hatzis P, Thiele A, Born van den M, Begthel H, Brabletz T, Taketo MM, Clevers H: Wnt signalling induces maturation of Paneth cells in intestinal crypts. Nat Cell Biol 2005, 7:381-6.

18. Flier Van der LG, Clevers $\mathrm{H}$ : Stem cells, self-renewal, and differentiation in the intestinal epithelium. Annu Rev Physiol 2009, 71:241-60.

19. Fujiwara $K$, Ochiai M, Ohta T, Ohki M, Aburatani H, Nagao M, Sugimura $T$, Nakagama $\mathrm{H}$ : Global gene expression analysis of rat colon cancers induced by a food-borne carcinogen, 2-amino-1-methyl-6-phenylimidazo [4,5-b]pyridine. Carcinogenesis 2004, 25:1495-505.

20. Flier Van der LG, Sabates-Bellver J, Oving I, Haegebarth A, De Palo M, Anti M, Van Gijn ME, Suijkerbuijk S, Wetering Van de M, Marra G, Clevers H: The Intestinal Wnt/TCF Signature. Gastroenterology 2007, 132:628-32.

21. Zucker S, Vacirca J: Role of matrix metalloproteinases (MMPs) in colorectal cancer. Cancer Metastasis Rev 2004, 23:101-17.

22. Andreasen PA, Kiøller L, Christensen L, Duffy MJ: The urokinase-type plasminogen activator system in cancer metastasis: a review. Int I Cancer 1997, 72:1-22.

23. Kermorgant S, Aparicio T, Dessirier V, Lewin MJ, Lehy T: Hepatocyte growth factor induces colonic cancer cell invasiveness via enhanced motility and protease overproduction. Evidence for PI3 kinase and PKC involvement. Carcinogenesis 2001, 22:1035-42.

24. Liuzzi JP, Cousins RJ: Mammalian zinc transporters. Annu Rev Nutr 2004, 24:151-72.

25. Song MK, Heng MC, Rolandelli R, Ament ME, Heng MK: Possible link between zinc intake and colon cancer. J Natl Cancer Inst 1993, 85:667-9.

26. Seya T, Tanaka N, Shinji S, Yokoi K, Koizumi M, Teranishi N, Yamashita K, Tajiri T, Ishiwata T, Naito Z: Lumican expression in advanced colorectal cancer with nodal metastasis correlates with poor prognosis. Oncol Rep 2006, 16:1225-30.

27. Beattie J, Allan GJ, Lochrie JD, Flint DJ: Insulin-like growth factor-binding protein-5 (IGFBP-5): a critical member of the IGF axis. Biochem J 2006, 395:1-19.

28. Reichling T, Goss KH, Carson DJ, Holdcraft RW, Ley-Ebert C, Witte D, Aronow BJ, Groden J: Transcriptional profiles of intestinal tumours in Apc (Min) mice are unique from those of embryonic intestine and identify novel gene targets dysregulated in human colorectal tumours. Cancer Res 2005, 65:166-76.

29. Hemers E, Duval C, McCaig C, Handley M, Dockray GJ, Varro A: Insulin-like growth factor binding protein-5 is a target of matrix metalloproteinase-
7: implications for epithelial-mesenchymal signaling. Cancer Res 2005, 65:7363-9.

30. Rho SB, Dong SM, Kang S, Seo SS, Yoo CW, Lee DO, Woo JS, Park SY: Insulin-like growth factor-binding protein-5 (IGFBP-5) acts as a tumour suppressor by inhibiting angiogenesis. Carcinogenesis 2008, 29:2106-11.

31. Takahashi M, Mutoh M, Kawamori T, Sugimura T, Wakabayashi K: Altered expression of beta-catenin, inducible nitric oxide synthase and cyclooxygenase-2 in azoxymethane-induced rat colon carcinogenesis. Carcinogenesis 2000, 21:1319-27.

32. Ohta T, Takahashi M, Ochiai A: Increased protein expression of both inducible nitric oxide synthase and cyclooxygenase-2 in human colon cancers. Cancer Lett 2005, 239:246-53.

33. Femia AP, Dolara P, Luceri C, Salvadori M, Caderni G: Mucin-depleted foci show strong activation of inflammatory markers in 1,2dimethylhydrazine-induced carcinogenesis and are promoted by the inflammatory agent sodium dextran sulfate. Int I Cancer 2009, 125:541-7.

34. Gebhardt C, Németh J, Angel P, Hess J: S100A8 and S100A9 in inflammation and cancer. Biochem Pharmacol 2006, 72:1622-31.

35. Stulík J, Osterreicher J, Koupilová K, Knízek, Macela A, Bures J, Jandík P, Langr F, Dedic K, Jungblut PR: The analysis of S100A9 and S100A8 expression in matched sets of macroscopically normal colon mucosa and colorectal carcinoma: the S100A9 and S100A8 positive cells underlie and invade tumour mass. Electrophoresis 1999, 20:1047-54.

36. Myung SJ, Rerko RM, Yan M, Platzer P, Guda K, Dotson A, Lawrence E, Dannenberg AJ, Lovgren AK, Luo G, Pretlow TP, Newman RA, Willis J, Dawson D, Markowitz SD: 15-Hydroxyprostaglandin dehydrogenase is an in vivo suppressor of colon tumourigenesis. Proc Natl Acad Sci USA 2006, 103:12098-102.

37. Ambs S, Merriam WG, Bennett WP, Felley-Bosco E, Ogunfusika MO, Oser SM, Klein S, Shields PG, Billiar TR, Harris CC: Frequent nitric oxide synthase-2 expression in human colon adenomas: implication for tumour angiogenesis and colon cancer progression. Cancer Res 1998, 58:334-41.

38. Barker N, Clevers H: Mining the Wnt pathway for cancer therapeutics. Nat Rev Drug Discov 2006, 5:997-1014.

39. The Wnt Homepage: Wnt target genes. [http://www.stanford.edu/ rnusse/pathways/targets.html]

40. Barker N, van Es JH, Kuipers J, Kujala P, Born van den M, Cozijnsen M, Haegebarth A, Korving J, Begthel H, Peters PJ, Clevers H: Identification of stem cells in small intestine and colon by marker gene Lgr5. Nature 2007, 449:1003-7.

41. McClanahan T, Koseoglu S, Smith K, Grein J, Gustafson E, Black S, Kirschmeier P, Samatar AA: Identification of overexpression of orphan $G$ protein-coupled receptor GPR49 in human colon and ovarian primary tumours. Cancer Biol Ther 2006, 5:419-26.

42. Biswas S, Chytil A, Washington K, Romero-Gallo J, Gorska AE, Wirth PS, Gautam S, Moses HL, Grady WM: Transforming growth factor beta receptor type II inactivation promotes the establishment and progression of colon cancer. Cancer Res 2004, 64:4687-92.

43. Muñoz NM, Upton M, Rojas A, Washington MK, Lin L, Chytil A, Sozmen EG, Madison BB, Pozzi A, Moon RT, Moses HL, Grady WM: Transforming growth factor beta receptor type II inactivation induces the malignant transformation of intestinal neoplasms initiated by Apc mutation. Cancer Res 2006, 66:9837-44

44. Biasi F, Mascia C, Poli G: The contribution of animal fat oxidation products to colon carcinogenesis, through modulation of TGF- $\beta 1$ signaling. Carcinogenesis 2008, 29:890-4

45. Massagué J: TGF- $\beta$ in Cancer. Cell 2008, 134:215-30.

46. Bachman KE, Park BH: Duel nature of TGF-beta signaling: tumour suppressor vs. tumour promoter. Curr Opin Oncol 2005, 17:49-54.

47. Höglund P, Haila S, Socha J, Tomaszewski L, Saarialho-Kere U, KarjalainenLindsberg ML, Airola K, Holmberg C, de la Chapelle A, Kere J: Mutations of the Down-regulated in adenoma (DRA) gene cause congenital chloride diarrhoea. Nat Genet 1996, 14:316-9.

48. Schweinfest CW, Henderson KW, Suster S, Kondoh N, Papas TS: Identification of a colon mucosa gene that is down-regulated in colon adenomas and adenocarcinomas. Proc Natl Acad Sci USA 1993, 90:4166-70.

49. Meer-Van Kraaij Van Der C, Van Lieshout EM, Kramer E, Meer Van Der R, Keijer J: Mucosal pentraxin (Mptx), a novel rat gene 10-fold downregulated in colon by dietary heme. FASEB J 2003, 17:1277-85. 
50. Munitz A, Seidu L, Cole ET, Ahrens R, Hogan SP, Rothenberg ME: Resistinlike molecule alpha decreases glucose tolerance during intestinal inflammation. J Immunol 2009, 182:2357-63.

51. Femia AP, Tarquini E, Salvadori M, Ferri S, Giannini A, Dolara P, Caderni G: K-ras mutations and mucin profile in preneoplastic lesions and colon tumours induced in rats by 1,2-dimethylhydrazine. Int J Cancer 2008, 122:117-23.

52. Mizoshita T, Tsukamoto T, Inada Kl, Hirano N, Tajika M, Nakamura T, Ban H, Tatematsu M: Loss of MUC2 expression correlates with progression along the adenoma-carcinoma sequence pathway as well as de novo carcinogenesis in the colon. Histol Histopathol 2007, 22:251-60.

53. Ortega AD, Sánchez-Aragó M, Giner-Sánchez D, Sánchez-Cenizo L, Willers I, Cuezva JM: Glucose avidity of carcinomas. Cancer Lett 2009, 276:125-35.

54. Halberg RB, Waggoner J, Rasmussen K, White A, Clipson L, Prunuske AJ, Bacher JW, Sullivan R, Washington MK, Pitot HC, Petrini JH, Albertson DG, Dove WF: Long-lived Min mice develop advanced intestinal cancers through a genetically conservative pathway. Cancer Res 2009, 69:5768-75.

55. Powell SM, Zilz N, Beazer-Barclay Y, Bryan TM, Hamilton SR, Thibodeau SN, Vogelstein B, Kinzler KW: APC mutations occur early during colorectal tumorigenesis. Nature 1992, 359:235-7.

56. Shibata H, Takano H, Ito M, Shioya H, Hirota M, Matsumoto H, Kakudo Y, Ishioka C, Akiyama T, Kanegae Y, Saito I, Noda T: Alpha-catenin is essential in intestinal adenoma formation. Proc Natl Acad Sci USA 2007, 104:18199-204.

57. Vermeulen SJ, Bruyneel EA, Bracke ME, De Bruyne GK, Vennekens KM, Vleminckx KL, Berx GJ, van Roy FM, Mareel MM: Transition from the noninvasive to the invasive phenotype and loss of alpha-catenin in human colon cancer cells. Cancer Res 1995, 55:4722-8.

58. Raftopoulos I, Davaris P, Karatzas G, Karayannacos P, Kouraklis G: Level of alpha-catenin expression in colorectal cancer correlates with invasiveness, metastatic potential, and survival. J Surg Oncol 1998, 68:92-9.

\section{Pre-publication history}

The pre-publication history for this paper can be accessed here: http://www.biomedcentral.com/1471-2407/10/194/prepub

doi:10.1186/1471-2407-10-194

Cite this article as: Femia et al:: Gene expression profile and genomic alterations in colonic tumours induced by 1,2-dimethylhydrazine (DMH) in rats. BMC Cancer 2010 10:194.

\section{Submit your next manuscript to BioMed Central and take full advantage of:}

- Convenient online submission

- Thorough peer review

- No space constraints or color figure charges

- Immediate publication on acceptance

- Inclusion in PubMed, CAS, Scopus and Google Scholar

- Research which is freely available for redistribution

Submit your manuscript at www.biomedcentral.com/submit
Biomed Central 